\title{
HOW SHOULD WE MEASURE THE “ECONOMIC” ASPECTS OF WELL-BEING?
}

\author{
BY LARS OSBERG*
}

Dalhousie University, Halifax, Nova Scotia

AND

ANDREW SHARPE

Center for the Study of Living Standards, Ottawa, Ontario

\begin{abstract}
The Human Development Index (HDI) uses GDP per capita to measure "command over resources," which implicitly makes the strong value judgment that inequality and insecurity do not matter. This paper presents revised estimates of the Index of Economic Well-Being (IEWB) for the United States, the U.K., Canada, Australia, Germany, Norway and Sweden for the period 1980 to 2001 and demonstrates that replacing an index of the log per capita incomes with our IEWB as the "command over resources" component in the Human Development Index (HDI) affects the level and trend of the HDI, even among affluent nations. Because the IEWB recognizes four dimensions of command over resources (Current effective per capita Consumption flows, Net societal Accumulation of stocks of productive resources, Income Distribution and Economic Security), its use has a particularly large impact where underlying trends in these components diverge (e.g. the U.K. or the United States).
\end{abstract}

\section{INTRODUCTION}

How should we measure the economic component of societal well-being?

In particular, since the UNDP's Human Development Index (HDI) is arguably the world's best-known index of societal well-being, is its use of per capita GDP to measure "access to economic resources" potentially misleading?

A major strength of social indicators such as the UNDP's HDI is their explicit recognition that there is much more to "well-being" than economics. However, the HDI also recognizes that a key component of overall well-being is "access to economic resources." Although national income accounting measures may sometimes not agree with popular perceptions of trends in economic

Note: Revised (and retitled) version of paper presented at WIDER Conference on Inequality, Poverty and Human Well-Being Helsinki, May 30-31, 2003 and at the Canadian Economics Association 2003 Annual Meetings. This paper is a significant revision and extension of work that has been previously presented at a number of conferences and published in several journals (e.g. Osberg and Sharpe 2002a, 2002b, 2003). We would like to thank the discussants at those meetings and the anonymous referees for their extensive comments. Jeremy Smith, Julia Salzman, Dimitry Kabelyan, Olivier Guilbaud and Lynn Lethbridge did outstanding work as research assistants and deserve much of the credit for all our work. Remaining errors are our responsibility. The sources for all figures in the text can be found in the data file associated with this paper, which is posted for free download at www.csls.ca/iwb/sources.pdf.

*Correspondence to: Lars Osberg, McCulloch Professor of Economics, Dalhousie University, 6214 University Avenue, Halifax, Nova Scotia B3H 3J5, Canada (lars.osberg@dal.ca). 
well-being, ${ }^{1}$ GDP per capita is one of the three main components of the Human Development Index, whose objective is to indicate the capability of people "to lead a long and healthy life, to acquire knowledge and to have access to resources needed for a decent standard of living" (UNDP, 2004, p. 127). ${ }^{2}$

In this paper, we are motivated by the idea that a better measure of "access to resources needed for a decent standard of living" is needed if economic and social trends are to be combined into an index with larger ambitions. In particular, we argue that a measure of "command over resources" should explicitly identify both average consumption and the aggregate national accumulation of productive resources and should include measures of income distribution and economic security. Although the importance of "sustainability" and intergenerational inheritance has long been a refrain of the environmental literature and although international debates on development and social policy increasingly recognize the importance of distributional issues - particularly poverty and social exclusionwe argue that these issues should not be considered in isolation, as if tradeoffs between them might not matter. We also think that the impact of economic insecurity on well-being has received too little attention-despite the precariousness of daily life for many inhabitants of poor countries and the manifest importance of welfare state risk reduction for the citizens of affluent nations. Hence, this paper summarizes a methodology for the construction of an Index of Economic WellBeing (IEWB), which provides consistent and simultaneous assessment of consumption, accumulation, distribution and security, and compares the implications of using the IEWB in place of GDP.

The paper is divided into three main sections and several appendices. Section 2 of the main text presents our revised estimates of the overall index and its components for the United States, the United Kingdom, Germany, Canada, Australia, Norway and Sweden from 1980 to $2001,{ }^{3}$ and compares trends in the Index and its components to trends in GDP per capita and the HDI. Section 3 examines how estimates of the HDI would differ if the IEWB were used to calculate the "economic" component of the HDI. Section 4 concludes.

${ }^{1}$ The paper (Osberg, 1985a) that originated our research was motivated by Solow's observation that in 1980 Ronald Reagan asked the American people a seemingly simple question: "Are you better off today than you were four years ago?" Although U.S. real GDP per capita was, in 1980, some 8.8 percent higher than in 1976, his audiences typically answered "No!" Our work is thus in the spirit of the Measure of Economic Welfare (MEW) developed by William Nordhaus and James Tobin (1972) over three decades ago.

${ }^{2}$ The HDI (UNDP, 2004) is a composite index with three equally weighted components: health, education, and "economic resources." All are scaled to a common unit range. The health component is captured by life expectancy at birth. The education component is calculated from the adult literacy rate and the combined primary, secondary, and tertiary gross enrollment rates (two-thirds of weight given to the former and one-third to the latter). "Economic resources" are expressed by the logarithm of GDP per capita, measured in purchasing power parity terms. In practice, this means that differences in average income among developing countries matter much more than income differences among high income countries. For the countries examined in this paper, GDP per capita is in a range where it makes little difference, in practice, whether one uses GDP or ln (GDP).

${ }^{3}$ These countries are selected because they have a large enough number of public-use micro-data files from the Luxembourg Income Study for construction of reliable long-run time series on certain of the variables we need. We note that maintaining international comparability of estimates has meant that some data used in other papers of ours (e.g. Osberg and Sharpe, 1998), and only available for Canada and the United States, have not been used in this paper. This implies that the estimates in this paper for Canada and the United States are not identical to those in these other papers. 
In contrasting GDP and the IEWB as measures of "command over resources" we do not intend to denigrate the importance of obtaining an accurate count of the total money value of goods and services produced for sale in the market in a given country in a given year (i.e. GDP). Clearly, GDP measurement is essential for many important public policy purposes (e.g. macroeconomic demand management or public finance). However, GDP accounting does omit consideration of many issues (for example, leisure time, longevity of life, asset stock levels) which are important to the command over resources of individuals. And although some of the compilers of the national accounts may protest that their attempt to measure the aggregate money value of marketed economic output was never intended as a full measure of economic well-being, it has often been used as such. Indeed, because statistics on GDP per capita are so easily available in comparable form for so many countries, the onus is on critics to show that alternative measures of "command over resources" are possible, plausible and make some difference.

In developing our Index of Economic Well-Being we are not arguing that "society's well-being" is a single, objective number (like the average altitude of a country). It is more accurate, in our view, to think of each individual in society as making a subjective evaluation of objective data in coming to a personal conclusion about society's well-being. Well-Being has multiple dimensions and individuals differ (and have the moral right to differ) in their subjective valuation of the relative importance of each dimension of well-being. ${ }^{4}$

Citizens are interested in evaluating the well-being of their country, partly because all adults are occasionally called upon, in a democracy, to exercise choices (e.g. in voting) on issues that affect the collectivity (and some individuals, such as civil servants, have to make such decisions on a daily basis). As well, individuals who identify with the wider community have an intrinsic interest in evaluating its well-being. Hence, although self-interest may play some role in each individual's evaluation of societal outcomes, ${ }^{5}$ citizens have a number of reasons to ask questions of the form: "Is my country 'better off'?" Because citizens differ in their values, an index of society's well-being will be more useful in helping individuals answer such questions if it can accommodate differences in evaluative weights.

Although conceptually there may be no way to measure some of the different dimensions of well-being in directly comparable units, as a practical matter citizens are frequently called upon to evaluate policies that favor one or the other. ${ }^{6}$

${ }^{4}$ Dasgupta (2001, pp. 5-7) suggests that debates over public policy are often driven by disagreements about policy efficacy rather than differences in the valuation of social states but Sen (1999, p. 81) has argued for: "the need to assign explicitly evaluative weights to different components of quality of life (or of well-being) and then to place the chosen weights for open public discussion and critical scrutiny." We believe that both casual empiricism and explicit public opinion surveys (e.g. the World Values Survey) provide abundant evidence for heterogeneity in values (for formal econometric analysis see Clark et al. (2003) or Osberg and Smeeding (2004)).

${ }^{5}$ Formally, if one thinks of individuals as wanting to maximize some index $\mathrm{I}=\alpha_{1}$ (own utility) + $\alpha_{2}$ (own estimate of society's well-being), then a measure of social well-being is useful unless $\alpha_{2}=0$ for all persons, always.

${ }^{6}$ For example, although "knowledge" and "health" are both important to individuals, they cannot be measured directly in comparable units. Nonetheless, citizens have to decide how much to spend on hospitals or on schools. 
TABLE 1

Dimensions of Economic Well-Being or Command over Resources

\begin{tabular}{|c|c|c|}
\hline \multirow[b]{2}{*}{ Concept } & \multicolumn{2}{|c|}{ Time Period } \\
\hline & Present & Future \\
\hline $\begin{array}{l}\text { "Typical citizen" or } \\
\text { "representative agent" }\end{array}$ & $\begin{array}{l}\text { Average flow of current } \\
\text { income }\end{array}$ & $\begin{array}{l}\text { Aggregate accumulation of productive } \\
\text { stocks }\end{array}$ \\
\hline Heterogeneous citizens & $\begin{array}{l}\text { Distribution-income } \\
\text { inequality and poverty }\end{array}$ & Insecurity of future income \\
\hline
\end{tabular}

Hence, individuals often have to come to a summative decision - i.e. have a way of "adding it all up" - across domains that are conceptually dissimilar. From this perspective, the purpose of index construction should be to assist individuals e.g. as voters in elections and as bureaucrats in policy making - in thinking systematically about national outcomes and public policy, without necessarily presuming that all individuals have the same values.

In our view, indices of social well-being can best help individuals to come to reasonable answers about social evaluations if information is presented in a way that highlights the objective trends in major dimensions of well-being and thereby helps individuals to come to summary judgments - but also respects differences in values. Although it may not be possible to define an objective index of societal well-being, individuals still have the problem (indeed, the moral responsibility) of coming to a subjective evaluation of social states, and they need organized, objective data if they are to do it in a reasonable way. ${ }^{7}$

The logic of our identification of four components of well-being is that it recognizes both trends in average outcomes and in the diversity of outcomes, both now and in the future, as Table 1 illustrates.

When an average flow like GDP per capita (or an alternative, such as average personal income or the GPI) is used as a summary index of well-being, analysis is stopping in the first quadrant - assuming that the experience of a representative agent can summarize the well-being of society and that the measured income flow optimally weights consumption and savings, so that one need not explicitly distinguish between present consumption flows and the accumulation of asset stocks which will enable future consumption flows.

However, if society is composed of diverse individuals living in an uncertain world who typically "live in the present, anticipating the future," each individual's estimate of national economic well-being will depend on the net accumulation of productive resources, broadly defined - which Dasgupta (2001) has called "genuine investment." GDP is a market income flow measure, which does not reveal the proportion of national income saved for the future. As well, consideration of the aggregate savings rate of market goods omits trends in many crucially important assets - such as the environment, research and development or human capital. There is little reason to believe that the national savings rate is automati-

${ }^{7}$ Although each individual may have their own personal subjective evaluation of societal outcomes, the distribution of such evaluations among others is an objective fact that is also often of interestbut for each person, the questions of (1) "what do I think is important?" and (2) "what do others (e.g. the median citizen/voter) think to be important?" are interesting for very different reasons. 
cally optimal. Indeed, if citizens have differing rates of time preference, ${ }^{8}$ any given savings rate will only be "optimal" from some persons' points of view. Hence, a better estimate of the well-being of society should allow analysts to distinguish explicitly between current consumption and the accumulation of productive assets (broadly defined), and thereby enable citizens to apply their differing values or time preferences.

As well, individuals are justifiably concerned about the degree to which they and others will share in prosperity. The Rawlsian maxi-min criterion of distributive social justice ${ }^{9}$ argues that social progress should be judged by the increase in well-being of the least advantaged. Although Rawls has been deservedly influential, this perspective does imply (if taken strictly) that income transfers from the middle classes to the elite do not matter, as long as the middle class do not themselves become the "most deprived." This seems to us to be an extreme argumentbut on the other hand, the welfare economics literature on "Social Welfare Functions" that argues that social welfare depends just on the average income and on the general inequality of incomes, implies there is no specific impact of poverty. ${ }^{10}$ Because we think both issues matter and because we want - in a way that will be transparent to readers who may not be technically sophisticated - to combine a concern for the least well off with a concern for inequality among the wider population, we argue that an index of Equality in income distribution should explicitly reflect both inequality and poverty.

Finally, if the future is uncertain, and if complete insurance is unobtainable (either privately or through the welfare state), individuals have reason to care about the degree to which the economic future is secure. The idea that individuals may be averse to risk is a direct consequence of diminishing marginal utility of income,

${ }^{8}$ Generally speaking, citizens can be expected to have a diverse range of opinions on intergenerational equity. Among professional economists, although many are attracted by the rule that there should be no decline in the total stock of capital per person, Solow (1974) noted many years ago that the optimal capital accumulation rule depends crucially on ethical position (e.g. Rawlsian or Ramsey/utilitarian?), technology assumption (static or progressive?) and assumed degree of substitutability between exhaustible natural resources and reproducible capital. Johansson (1991, p. 98) is among those who have concluded that: "The distribution across generations is a normative issue in the same sense as is the distribution within generations. The difference is that those not yet born are unable to "vote' for their interests ... their utility functions are our projections of these functions." In this paper we do not presume that the current rate of accumulation is either optimal or "too high" or "too low." However, we do suggest that if citizens are to evaluate national well-being, they must take a specific position about the relative valuation of capital accumulation versus current consumption (or greater equality or security). Note that by summing the value of different types of natural resources and reproducible capital, human capital, etc., we are implicitly assuming the substitutability of asset types (sometimes called the Hartwick rule)—which implies a rejection of "specific conservationism." We also note that Dasgupta concludes that the rate of change of social well-being will equal the rate of "genuine investment" (2001, p. 272), but this result depends crucially on his assumption of " $\alpha$ autonomy," which rules out the consideration of distribution and security which we advocate.

${ }^{9}$ Rawls himself put this as a secondary priority. He saw a just society as incorporating two principles - the equal right of all citizens to basic liberties (primary goods) and a maxi-min criterion of distributive justice with respect to income. As he put it: "The first principle has priority over the second, so that all citizens are assured the equal basic liberties; similarly part (b) of the second principle (i.e. fair equality of opportunity) has priority over part (a) (i.e. the maxi-min principle)" (1982, p. 162).

${ }^{10}$ Chapters 4 and 5 of Lambert (1989) provide a nice summary of the Social Welfare Function literature - as he notes (1989, pp. 124-8), an additively separable social welfare function in which inequality is summarized by the Gini index (as in the IEWB) is consistent with an underlying individual utility function which depends on relative deprivation - which may have either an envious or an altruistic motivation. 
and implies that individuals gain in certainty equivalent income from the availability of public and private insurance, even if insurance is costly. We emphasize that security is of value to all citizens - not just those at risk of poverty. ${ }^{11}$

These four components therefore have a logical rationale and a manageable number of headings. If the objective of index construction is to assist public policy discussion, one must recognize that when too many categories have to be considered simultaneously, discussion can easily be overwhelmed by complexity. We therefore do not adopt the strategy of simply presenting a large battery of indicators. $^{12}$ In this sense, our approach is similar to that of Atkinson et al. (2002, p. 70) who advocate the presentation of a restricted number of "Level 1" indicators, supported by a larger number of "Level 2" indicators. However, our approach is more "economic" in its focus, both because we emphasize the logical link between indicators and because the theme of resource availability is the central concept in all four dimensions of economic well-being (which, we repeat, is only part of social well-being).

Because reasonable people may disagree in the relative weight they would assign to each dimension - e.g. some will argue that inequality in income distribution is highly important while others will argue the opposite-we argue that it is preferable to be explicit and open about the relative weights assigned to components of well-being, rather than leaving them implicit and hidden. ${ }^{13}$ (An additional reason to distinguish the underlying components of economic well-being is that for policy purposes it is not particularly useful to know only that well-being has gone "up" or "down," without also knowing which aspect of well-being has improved or deteriorated.) We specify explicit weights to the components of economic well-being, and test the sensitivity of aggregate trends to changes in those weights, in order to enable others to assess whether, by their personal values of what is important in economic well-being, they would agree with an overall assessment of trends in the economy.

The idea that a society's economic well-being depends on total consumption and accumulation, and on the individual inequality and insecurity that surround the distribution of macroeconomic aggregates is consistent with a variety of theoretical perspectives. A sufficient set of conditions for the index of economic wellbeing which we propose would, for example, be that societal economic well-being be represented as the well-being of an agent who: (1) has a risk-averse utility function (i.e. diminishing marginal utility); (2) chooses, from behind a "veil of ignorance" as to his/her own characteristics, an individual income stream (and prospects of future income) from the actual distribution of income streams; (3) has a utility function in which both personal consumption and bequest to future

\footnotetext{
${ }^{11}$ Less affluent households may face higher probabilities of adverse events (like unemployment) and often have fewer protections (like access to credit) from their consequences - but even if their need is less, affluent households also benefit from social insurance, and such benefits deserve consideration in an index of economic well-being. In this, we diverge from the approach of Atkinson et al. (2002, p. 111) whose emphasis is solely on the risk of poverty.

${ }^{12}$ The "dashboard" strategy of multiple indicators can be seen in operation at http://esl.jrc.it/dc/.

${ }^{13}$ Current versions of the Genuine Progess Indicator (Cobb et al., 1985) and early versions of the HDI (see Anand and Sen, 2000, p. 94) weight average "income" by changes in the Gini index. This presumes a common valuation of economic equality among all citizens (which suggests the puzzleif everyone has the same preferences for equality - why the political system does not generate it).
} 
generations are valued; (4) has an individual income stream which is exposed to uninsurable and unpredictable future shocks; and (5) lives in a world in which capital markets and public policies do not always automatically produce a socially optimal aggregate savings rate. ${ }^{14}$

In a series of papers (Osberg and Sharpe, 2002a, 2002b) we have described the calculation of the four components or dimensions of economic well-being:

(1) Effective per capita consumption flows - which differs from the consumption of marketed goods and services included in GDP by including the value of government services and adjusting effective per capita consumption flows to account for household production, changing household economies of scale, leisure and life expectancy.

(2) Net national accumulation of stocks of productive resources - which adds net changes in the value of natural resources stocks, environmental costs, net change in level of foreign indebtedness, net accumulation of human capital and R\&D investment to the net investment in tangible capital and housing stocks now measured in GDP.

(3) Income distribution - the intensity of poverty (incidence and depth) and the inequality of income. ${ }^{15}$

(4) Economic security - from the financial implications of job loss, illness, family breakup and from poverty in old age.

Each dimension of economic well-being is itself an aggregation of many underlying trends, on which the existing data is of variable quality - and often differs across countries. By contrast, the System of National Accounts has had many years of development effort by international agencies (particularly the UN and the IMF), and has produced an accounting system for GDP that is rigorously standardized across countries. However, using GDP per capita as a measure of "command over resources" implicitly:

(1) assumes that the aggregate share of income devoted to accumulation (i.e. "genuine investment" in the public and private capital stock, human capital, research and development and environmental assets) is automatically optimal; and

(2) sets the weight of income distribution and economic insecurity to zero, by ignoring entirely their influence.

Neither assumption seems justifiable, and neither is innocuous.

\section{Estimates of Economic Well-Being Over Time And Across COUNTRIES}

The trend and level of any index are determined by the choice of variables that are included in the index, the trends and levels of those variables, and the weights they receive. Since we want to ensure that individuals with different values/preferences regarding the components of economic well-being can still find

\footnotetext{
${ }^{14} \mathrm{~A}$ fuller discussion can be found in Osberg (1985b).

${ }^{15}$ In keeping with our focus on "command over resources" we emphasize measures of poverty and income distribution rather than the broader concept of social exclusion, whose essential nature may sometimes refer to relations among people rather than command over resources (e.g. purdah, deafness, wheelchair accessibility).
} 
our methodology useful, we identify separately the four main dimensions of average current consumption, asset accumulation/sustainability, inequality/ poverty and insecurity. With a simple spreadsheet, it is easy to conduct sensitivity analyses of the impact on comparative levels of well-being of different weighting of these dimensions. ${ }^{16}$ However, for discussion purposes, we have to start somewhere and our "base" weighting gives each component an equal weight of 0.25. Readers who are familiar with some of our earlier work (e.g. Osberg and Sharpe, 2002a, 2002b) should be aware that the current paper presents results which embody a different scaling methodology. In the current paper, each component is scaled linearly to the $[0,1]$ interval - which has the important implication that in this paper we are now able (like the HDI) to make level comparisons across countries, as well as the comparisons of within-country rates of change which were the focus of our previous work.

We recognize that our methodology makes strong demands of the data and we are acutely conscious that the data sources available to us are far from what we would like. There is no escaping the fact that paying attention to more of the dimensions of economic well-being means that we need better data. As a practical matter, our attempt to incorporate income distribution and insecurity means that currently only a few affluent nations with well-developed statistical systems can be examined. These tend to be countries that also have more developed "welfare states," and it has often been suggested (e.g. Barr, 2001) that the basic objective of the welfare state has been to reduce economic insecurity and economic inequality.

Writing in 1931, before the development of the welfare state in the U.K., R. H. Tawney argued that: "Contrasts of economic security, involving, as they do, that, while some groups can organize their lives on a settled plan with a reasonable confidence that the plan will be carried out, others live from year to year, week to week, or even day to day, are even more fundamental than contrasts of income" (1964, p. 147). Since that time, a good deal of evidence - not least from the studies of the determinants of self-reported happiness available at "The World Database of Happiness" (Veenhoven, 2004) — has concluded that satisfying long-term personal relationships in a supportive community are crucial to personal well-being. Since such relationships are far harder to maintain when economic life is more insecure, it is arguable that insecurity and inequality are more important to personal well-being than the average level of consumption.

Nevertheless, data availability constrains the empirical estimates of this paper to affluent developed countries. As a consequence, although this paper stresses the importance of inequality and insecurity to economic well-being, the sample of

${ }^{16} \mathrm{An}$ Excel spreadsheet with the required data and programs is available at http://www.csls.ca/iwb.asp to enable readers to experiment with the implications of their own preferences. If such sensitivity analysis produces the same rankings of policy options, it is useful information to the policy process to know that differences in individual values do not matter to policy choices. If sensitivity analysis sometimes produces changes in policy rankings, it is useful to know how much one has to weight a particular dimension of well-being (e.g. inequality) if the rankings of alternative policy options are to be reversed. Since a good deal of the public debate in democracies concerns which values should take precedence, the sensitivity of policy rankings to evaluative weights is useful information to such debates. 


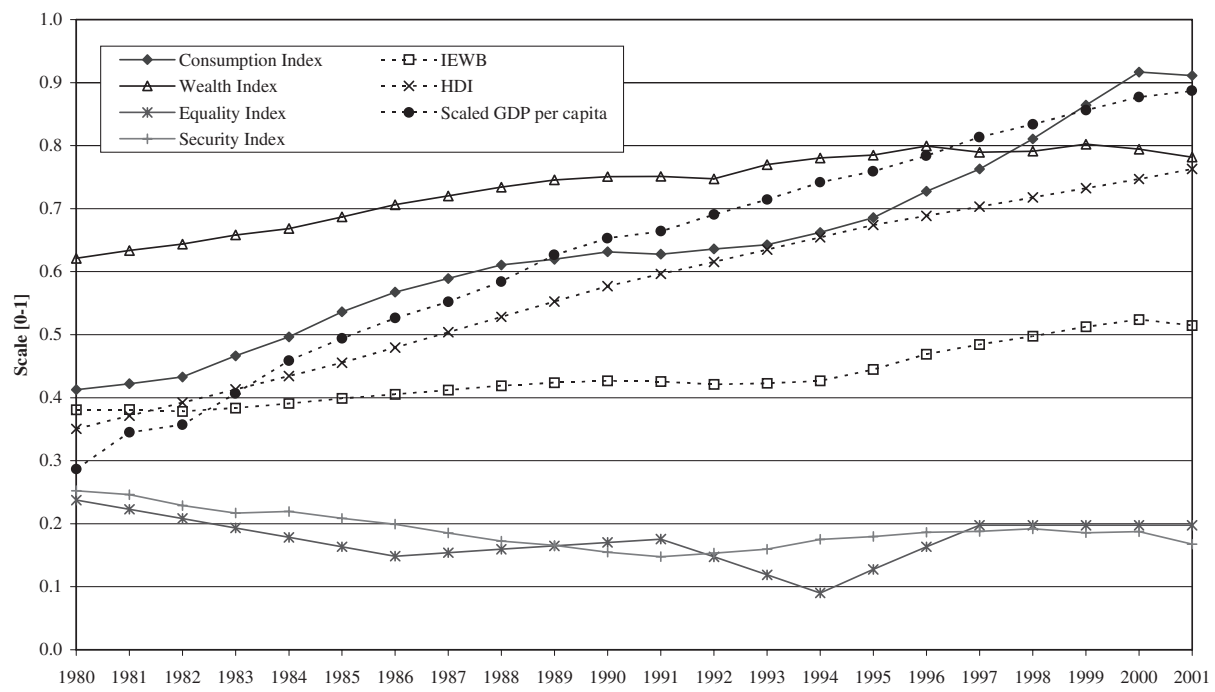

Figure 1. Index of Economic Well-being and Components, HDI and Scaled GDP per Capita Index in the United States, 1980-2001

nations that we use is arguably the group of nations in the world within which there is the least inequality and insecurity - which is unfortunate since the prevalence of poverty and the precariousness of economic life, and its impact on economic well-being, are undoubtedly far greater in many of the world's poorer nations. ${ }^{17}$ The selectivity of our sample that is forced by this data availability arguably implies that the estimates of this paper understate the difference that use of the IEWB, compared to GDP per capita, would make to measurement of economic well-being in a wider sample of countries.

However, we note that the increase in recent years in high quality micro-data from household surveys in poor nations is quite remarkable - so there is some hope that available statistical data may improve over time, enabling better estimates of well-being from a wider range of nations in the future. The objective of the present paper is to give a preliminary indication now of trends in economic well-being from a broader perspective than that provided by GDP accounting and to provide a motivation for future data collection - e.g. to better measure economic security.

Figures 1 to 3 present for three illustrative countries (the United States, United Kingdom and Norway) the four components of economic well-being and a "base" weighting, which assigns equal weight to each component of the aggregate index. For each country, we compare trends in the "base" index with trends in GDP per capita and in the Human Development Index. In all cases, we present scaled values

\footnotetext{
${ }^{17}$ Since the objective bases of economic insecurity (e.g. crop failure or cyclical unemployment) vary in relative importance as economic development progresses, measurement of "economic insecurity" should reflect these differences - implying that better data on economic security should also sometimes be different data. As well, we would prefer not to have to rely on interpolation between the periodic data points available in the Luxembourg Income Study, since that implies we cannot detect short period fluctuations in the distribution and security components of our index.
} 




Figure 2. The Index of Economic Well-being and Components, HDI and Scaled GDP per Capita Index in the United Kingdom, 1980-2001

using the Linear Scaling methodology. ${ }^{18}$ Figures 1 to 3 show the level in each year of each component of economic well-being (i.e. consumption, accumulation, distribution and economic security) as well as the level of the aggregate Index of Economic Well-Being when each component receives equal weight.

Figure 1 looks at the United States from 1980 to 2001, with dashed lines marking the level of aggregate indices (the HDI, GDP and the IEWB) and solid lines representing the components of the IEWB (consumption, accumulation, equality and economic security). It is notable that although the United States ranks highly on the scaled index value of GDP per capita, whose trend tracks the HDI fairly closely, the U.S. Index of Economic Well-Being shows a lower level and a flatter trend over the period. In the ranges of values observed among the seven countries examined here, the relative position of the United States in consumption, wealth stocks, equality and security differs considerably. Average consumption and aggregate wealth are comparatively high, with a strong upward trend for consumption. However, compared to the other six countries examined here, the

${ }^{18}$ The sources for all figures in the text can be found in the data file associated with this paper, which is posted for free download at www.csls.ca/iwb/sources.pdf. This paper (unlike our earlier papers developing the IEWB) uses the Linear Scaling technique - as also used in many other indices (including: the Human Development Index, the Index of Social Health, the Index of Economic Freedom etc.) - to standardize the range of variables to the $0-1$ interval. If the possible minimum and maximum of the range of a variable for all time periods and for all countries are denoted Min and Max, when a variable increase corresponds to an increase in overall welfare, the variable, VALUE, is scaled as $\frac{\text { Value-Min }}{\text { Max-Min }}$. When an increase in VALUE corresponds to a decrease in welfare, the complementary formula is used. Both maximum and minimum are set at the actual extremes of the values observed in all countries and all years of the present study, plus (or minus) 10 percent of the actual observed range. To keep all our comparisons on a common footing, for both the HDI and GDP per capita we use the [Max-Min] range defined by data from the same seven countries for which we construct the Index of Economic Well-Being. 


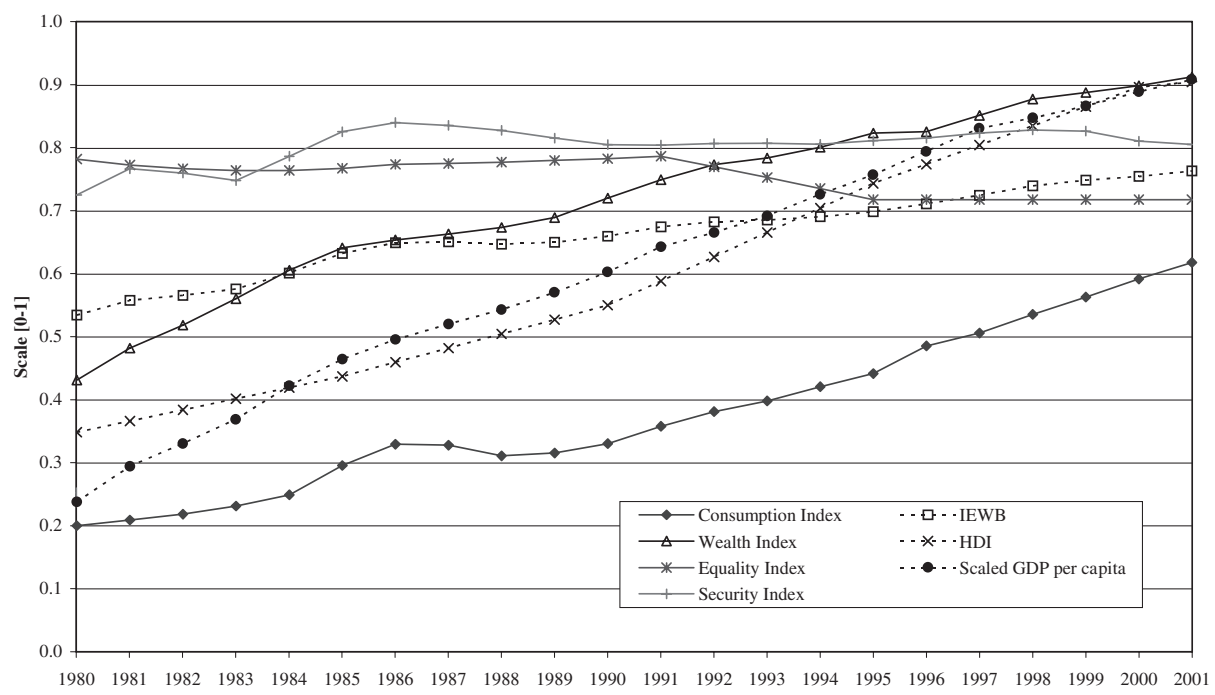

Figure 3. The Index of Economic Well-being and Components, HDI and Scaled GDP per Capita Index in Norway, 1980-2001

United States sits low in the range of observed equality and security, with a downward trend over time. As a consequence, when all four components are weighted equally in the IEWB, relatively poor attainment in the observed ranges of equality and security offsets the high level and upward trend of average consumption and aggregate wealth - with the result that the aggregate Index of Economic Well-Being is quite flat until about 1994, and only grew appreciably in the latter 1990s.

Figure 2 examines the United Kingdom. The same strong upward trend in both the HDI and GDP per capita indices is observed. However, over the 1980 to 2001 time period the United Kingdom experienced much sharper-and more divergent - changes in several of the components of economic well-being than did the United States. Equality declined steeply in the $1980 \mathrm{~s}^{19}$ (albeit from a higher base than in the United States) while average effective consumption rose considerably (from a relatively low base). Hence, as the ongoing public debate in the U.K. on the legacy of the Thatcher years also indicates, one's perception of how it all adds up for Britain depends heavily on one's values - how strongly one emphasizes the gains in mean consumption, compared to the losses in equality over this period. If these trends are equally weighted, the overall trend in the IEWB is fairly flat. The United Kingdom is a prime example of the fact that when underlying trends in the components of economic well-being diverge, the weights assigned to those components matter. ${ }^{20}$ In particular, assigning a zero weight to trends in

\footnotetext{
${ }^{19}$ Atkinson (2002, p. 12) has remarked on the "sheer magnitude of the rise" in the U.K. Gini index of income inequality from 1984 to 1990.

${ }^{20}$ We note that it is also useful to know when the relative valuation of components does not matter much - i.e. when consumption, accumulation, equality and security all have similar trends (e.g. during a business cycle downturn).
} 


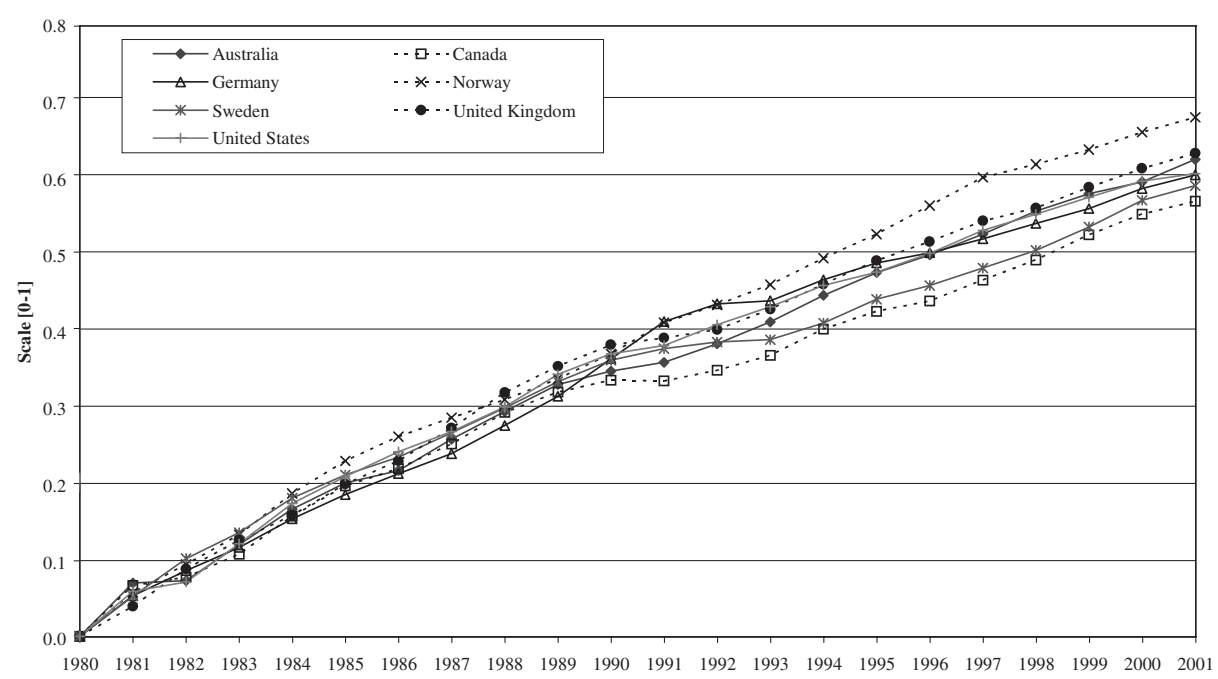

Figure 4. Absolute Change in Scaled GDP per Capita in Selected OECD Countries, 1980-2001

inequality, as use of GDP per capita implicitly does, matters a great deal to the evaluation of social well-being in the U.K.

By contrast to the United Kingdom and the United States, Figure 3 illustrates Norway's relatively high and fairly stable score in the international range of equality and security. Strong upward trends in average consumption and aggregate wealth stocks in Norway, combined with the lack of a strong trend in equality and security, implied that the equally weighted Index of Economic Well-Being had a high level and a rising trend. Because Norway is a small country with substantial petroleum revenues, the level of GDP and per capita incomes was inflated during the 1970 s by the rapid increase in oil prices - but the period examined by this paper (1980-2001) saw a collapse of real oil prices after 1985, and substantial volatility in the 1990s. Norwegian macro policy has attempted to smooth the impacts of such volatility on households, and the steadiness of trends is remarkable.

Figures 4 and 5 are included to illustrate how the perception of comparative trends in "command over resources" is altered when one looks only at GDP per capita (Figure 4) or the equally weighted Index of Economic Well-Being (Figure 5). The relative similarity of GDP per capita trends, and the divergence between countries in trends in the IEWB are notable. As well, as our previous work (Osberg and Sharpe, 2002b) has concluded, the trend to greater inequality and insecurity within countries implies that within nations, the cumulative increase in GDP per capita is in all instances substantially greater than the increase in the IEWB.

In Figure 6, the level of the IEWB for each of the seven countries, in each year from 1980 to 2001, is compared. However, should one compare trends over time or the level of "command over resources" at a point in time? Since countries are starting from very different levels of each variable, it may be more informative to consider change over time, as in Figure 5, rather than the level at any given time, as in Figure 6. Arguably, public policy cannot do much now to affect the initial 




Figure 5. Index of Economic Well-being Absolute Changes since 1980, Equal Weighting, 1980-2001

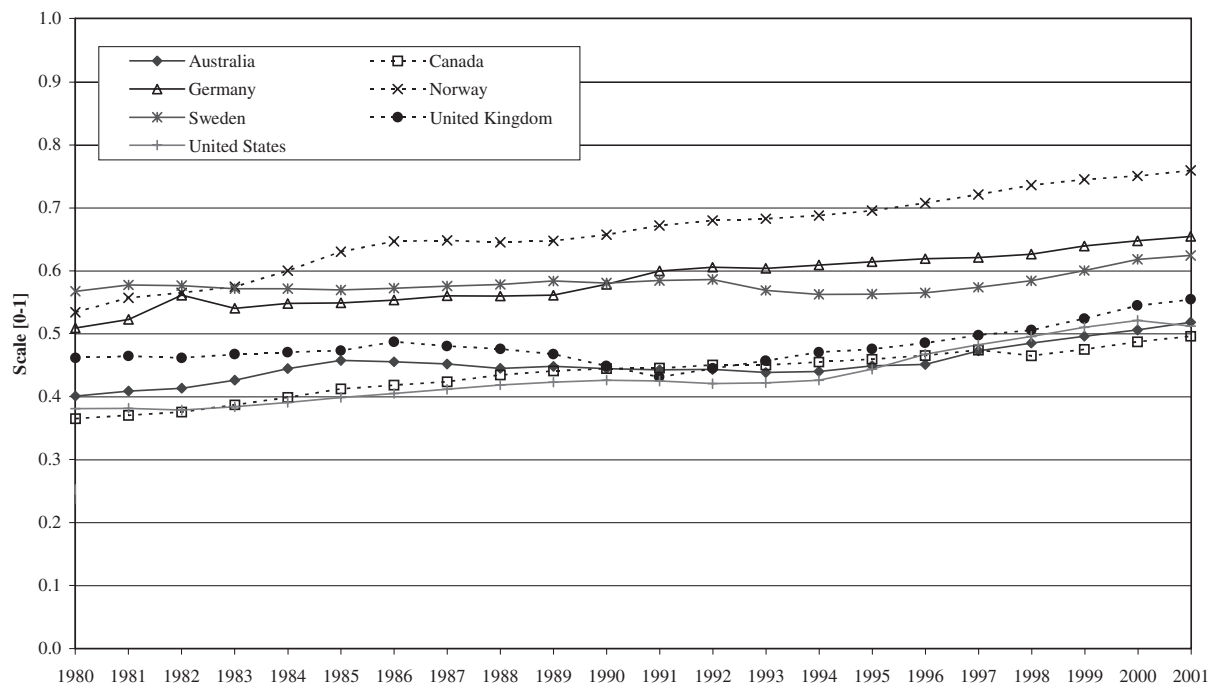

Figure 6. Index of Economic Well-being Scores in Selected OECD Countries, Equal Weighting, 1980-2001

endowment of nations, ${ }^{21}$ but public policy can affect how well that endowment is used-which would imply that it is the change over time, not the level, of economic well-being which reveals whether a nation is doing "well" or "poorly" in its policy decisions. However, it is clear that the annual country rankings of the level

${ }^{21}$ For example, Canada will always be the colder, rockier part of North America, with an unavoidable impact on agricultural productivity and heating bills. 
of the HDI have attracted a great deal of media and public interest. Despite our continuing concerns regarding the international similarity of statistical sources, this paper therefore presents comparisons of both the trend over time and crosscountry level of economic well-being.

In some instances, both the level comparisons of Figure 6 and the change comparisons of Figure 5 tell a common story. Norway has both the highest 2001 level of the IEWB and the largest positive change from 1980 to 2001 because it started in 1980 with a high level of equality and security (which was largely maintained) and had strong upward trends in consumption and accumulation. Norway therefore ends up with top ranking, in both Figure 5 (growth of economic wellbeing) and Figure 6 (level of economic well-being).

By contrast, because the United States had downward trends in equality and security, in Figure 5 the "base" equally weighted IEWB shows very little improvement from 1980 to 1994. Only in the latter 1990s does one see much growth in the IEWB for the United States, due to strong growth in consumption and accumulation from 1995 to 2001. Over the period 1980 to 2001 as a whole, growth in the IEWB in the United States was clearly outpaced by that in Norway, fairly similar to that in Germany, Canada, and Australia, and superior to growth in the United Kingdom, and Sweden. From a growth perspective, Sweden does least well of the seven countries compared, with relatively small consumption gains to offset a slight decline in economic security-but the choice between a comparison of levels (Figure 6) and a comparison of changes (Figure 5) can be very important for perceptions. By 2001, the level of the IEWB in Sweden had been surpassed by Norway and by Germany, but the influence of Sweden's initial position was strong enough that it had slipped only to third in the level rankings.

If the concern is with the level of economic well-being, the high base from which inequality and insecurity started in the United States and Canada is sufficient to place those countries in the bottom rank in the level of IEWB comparisons of Figure 6, along with Australia. Canada does not do badly in growth of well-being (Figure 5) but Canada started from an initial position of relatively high inequality and insecurity. Hence, in terms of level of economic well-being, Figure 6 indicates that Canada ends up in 2001 in the same relative position as in 1980 at the bottom.

The common element in Figure 5 is that for all countries, consideration of accumulation, inequality/poverty and economic insecurity reduces the measured rate of growth of economic well-being, compared to the use of the GDP per capita index. In general, the more heavily current average consumption is emphasized, the closer our IEWB index approaches GDP per capita. However, in every instance the consideration of a wider range of issues than those recognized in GDP accounting reduces the measured increase in economic well-being.

In some countries, the change in the perception of trends in well-being is striking. In the United States, from 1980 to 2001 GDP per capita increased by approximately 0.6 points (where the range of GDP per capita is represented as a $[0,1]$ interval), but our overall "base" Index of Economic Well-Being is much flatter, with a total increase of 0.13 points over the period. In the United Kingdom, the increase in per capita GDP was similar to that of the United States ( 0.63 points), but the Index of Economic Well-Being, equally weighted (i.e. including equal 
emphasis to economic inequality and insecurity) shows an increase of only 0.095 points. Both the United States and the United Kingdom have been marked by a substantial increase in economic inequality over this period, and increases in money income have been limited to the top end of the income distribution (see Osberg, 2003a,b). As well, increases in money income in the United States have been partially obtained at the cost of substantial increases in working hours. Hence, this is a reasonable finding.

\section{How Much Does Measurement of "Economic" Aspects of Well-Being Matter for Broader Measures of Well-Being?}

How much do different measures of "command over resources" affect a broader concept of societal well-being, such as the Human Development Index (HDI)? Figures 7 and 8 are presented in order to illustrate the level and trend of the HDI under two assumptions:

(1) that GDP per capita is an appropriate measure of "command over resources"22 (Figure 7) - as in the HDI as published by the UNDP — for present purposes one can call this the HDI-GDP; and

(2) that the equally weighted IEWB is the appropriate measure of "command over resources" (Figure 8) - which can be called HDI-IEWB.

In thinking about both the HDI-GDP and the HDI-IEWB, we are interested in which index of economic well-being is the best indicator of command over resources as part of a larger index of well-being. We understand the inclusion of education and life expectancy in the Human Development Index to be motivated by the idea that life in itself is valuable, and that education is valuable partly because it increases the human capability to lead a life of understanding and meaning-i.e. greater knowledge is in itself an aspect of a good life (see Anand and Sen, 2000).

\footnotetext{
${ }^{22}$ The HDI is calculated by the UNDP for 175 United Nations member countries every year, although the underlying methodology has changed slightly a number of times. Fortunately, estimates based on the most recent methodology have been published for 1970, 1975, 1980, 1985, 1990, 1995, 2000 and 2002. The HDI applies the linear scaling technique to each of its three components using minimum and maximum values based on values in all 175 countries covered by the HDI. Since the seven countries discussed in this paper all have high levels of GDP per capita, adult literacy, school enrolment and life expectancy relative to most of the other 175 countries, their HDI scores tend to be clustered closely together at the top of the range. Due to data availability, the IEWB uses observed values in only these seven countries, applying the linear scaling technique, and the IEWB scores are much more widely dispersed than the HDI scores.

Linear interpolation has been applied to the UNDP estimates, re-scaling the HDI scores in each year for these seven countries in order to make them comparable with the IEWB scores. The minimum value was the lowest observed HDI score amongst the seven countries in all years covered, minus 10 percent of the difference between the highest and lowest observed scores. A maximum value was chosen in a similar way, and the linear scaling technique was used to re-scale the HDI so as to be comparable with the IEWB. In order to ascertain how much difference the use of GDP per capita, compared to the IEWB, would make for the seven country sample, the GDP per capita component was re-scaled in the same manner as just discussed for the overall HDI. The re-scaled HDI using the IEWB as the command over resources variable was then calculated by subtracting one third of the re-scaled GDP per capita component from the re-scaled HDI, then adding one third of the scaled IEWB to the result. Implicitly, this choice of range increases the relative magnitude of inter-country differences in GDP among these seven countries.
} 


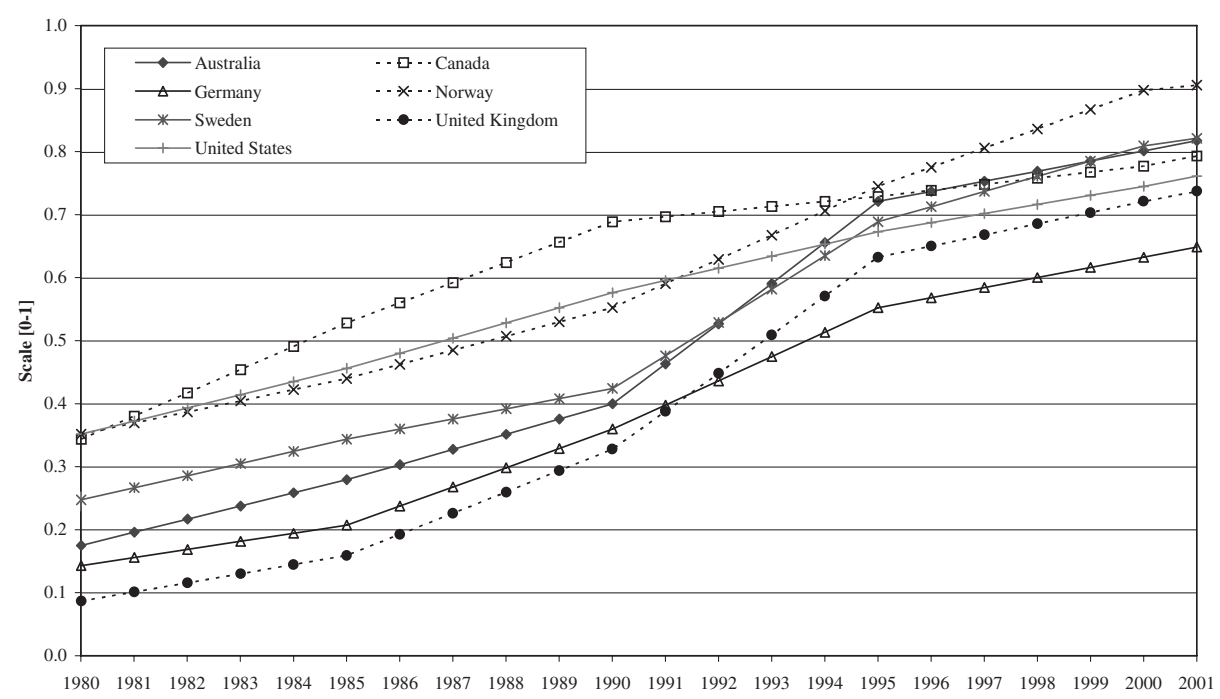

Figure 7. Human Development Index Using GDP per Capita, 1980-2001

On this basis, both life expectancy and education are included as separate arguments in the HDI index of well-being, and in the seven countries examined both education levels and life expectancy have trended up strongly over the last twenty five years. However, aspects of both are also part of GDP per capita and the IEWB. Measured GDP, for example, includes both the expenditure of resources on schooling and the increment to money income produced by education. The IEWB includes the stock of assets that will produce "command over resources" in future years-hence it includes estimates of the dollar value of "human capital" in the stock of education. Similarly, measured GDP includes both health care expenditures and the income produced by individuals who recover from illness, while the IEWB weights annual consumption by expected lifetimes. However, the HDI thinks of education and longer life expectancy as contributing to well-being over and above their contribution to more "command over resources"-i.e. more consumption over more years. Hence, neither the HDI-GDP or HDI-IEWB is "double-counting" the contributions of education and life expectancy to well-being. Instead, the HDI aims at measuring "human development," part of which involves greater command over resources.

In Figure 7 the estimates of HDI using GDP show little difference between Canada, Sweden, the United States, and the United Kingdom, reflecting the close similarity of the gross school enrolment rates and the limited ability of GDP per capita and life expectancy to differentiate among them. However, among these four countries, the type, level and extent of welfare state policies to reduce inequality and insecurity are quite dissimilar, with Sweden and the United States at the extremes and the United Kingdom and Canada as intermediate cases. (As Phipps (Phipps, 2002; Phipps and Curtis, 2003) has noted, the social policy differences among these countries do matter - e.g. for a wide variety of indicators of child well-being and functioning, for the well-being of mothers and for child health 


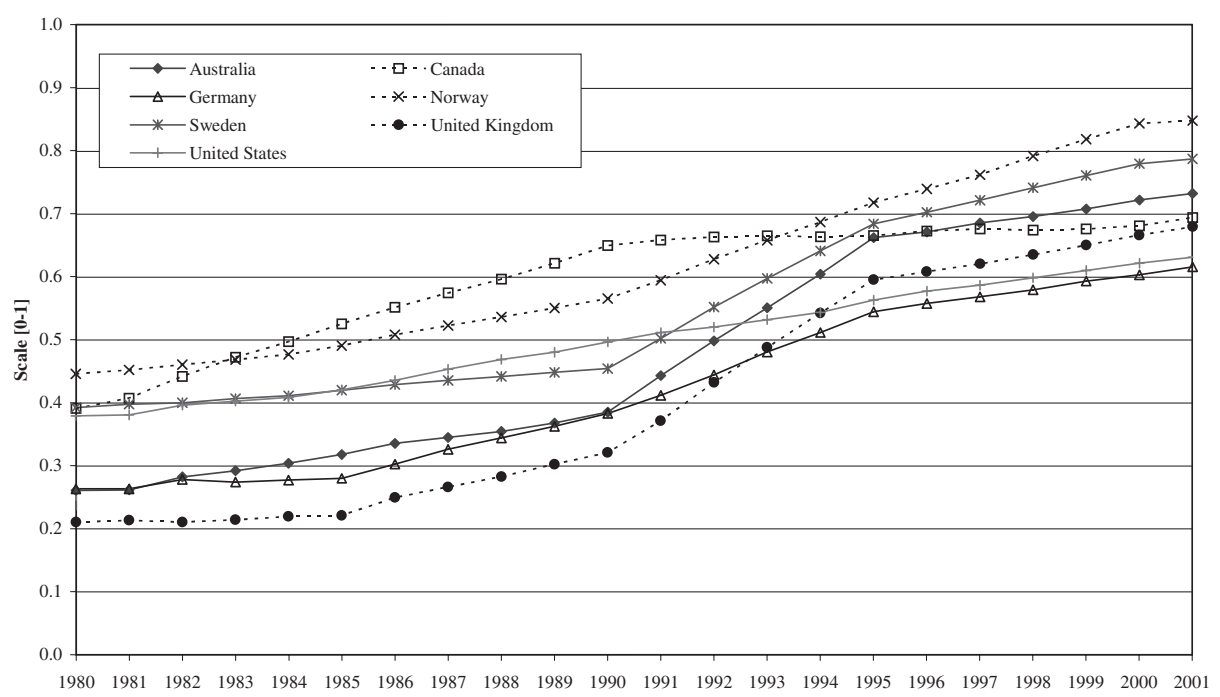

Figure 8. Human Development Index Using the Index of Economic Well-being, 1980-2001

status measures such as obesity.) Figure 8 illustrates the trends when the HDI incorporates an index such as the IEWB that can reflect differences in inequality and insecurity.

Using the HDI-IEWB, the ranking of countries in 2001 is clear-Norway dominates Sweden, which dominates Australia and Canada at the top of the rankings. Next in line comes the United Kingdom. Finally, if one weights equally current consumption sustainability equality and security, as well as accounting more exactly for average effective personal consumption and asset accumulation, the much greater inequality and insecurity of American life outbalance its higher GDP per capita, putting it second last in 2001 among the nations examined here. ${ }^{23}$

Notably, comparisons between specific pairs of countries often change when one uses the HDI-IEWB rather than the HDI-GDP (as one might expect, given the variation across these seven countries in social policy). Using the HDI-GDP, one would rank the United States marginally ahead of the United Kingdom in 2001 while according to the HDI-IEWB, the United Kingdom clearly dominates the United States. Using the HDI-GDP, Sweden and Australia are estimated to have very much the same level of well-being in 2001, but using the HDI-IEWB, Sweden clearly dominates Australia.

\section{CONCLUSION}

This paper has been about how we should include economics - the command over resources - in an index of societal well-being, but it is also useful to consider why such an index should be constructed. If people only cared about their personal well-being, and only made decisions about their own lives, then one could

${ }^{23}$ This result depends crucially on the weight placed on inequality and insecurity in calculation of the IEWB. 
assume that individuals can be trusted to calculate what is in their own self-interest - and there would be no point to calculating an index of society's well-being. However, if citizens are concerned with the community's well-being (perhaps because they sometimes exercise choices (e.g. in voting) on issues that affect the collectivity) they have reason to ask questions of the form: "Is the country better off?" The motivation for this paper is the idea that a better index of well-being may help citizens to organize their perceptions of social and economic outcomes and thereby help them make better political and public policy evaluations, according to their own valuations of outcomes.

If the purpose of an index of well-being is to help citizens think systematically about public policy, communicability is key. In this respect, the measurement of economic and social well-being differs fundamentally from measurement in some other domains, such as the natural sciences. Public communicability is of little concern to measurement issues (such as the mass of sub-atomic particles) which are intermediate steps in the work of elite researchers with the skills (e.g. the mathematics training) and the time to digest highly abstract and complex measures - but the whole point of constructing an index of societal well-being is lost if it is only used by specialist researchers.

Hence, "Keep it Simple" is a useful slogan in index construction, and the constraint of use in the public debate means that it is crucial for an index of wellbeing to have an intuitive justification that can be easily communicated. We think that there is an intuitive appeal to identifying the dimensions of current consumption, asset accumulation/sustainability, equality and economic security - and we hope that our presentation has been "simple enough" to be communicable (while still complex enough to be accurate).

We think that one can easily justify the idea that citizens are "better off" economically when consumption is sustainable, when total income is more equitably shared and when individuals have more security in their economic lives. Indeed, it would otherwise be hard to understand why modern welfare states developed. We therefore think that the Index of Economic Well-Being has a better claim to indicating the "command over resources" of a nation's citizens than GDP per capita, which is blind to the genuine savings rate and to inequality and insecurity. However, it is also clear that nations differ substantially in efforts to reduce inequality and insecurity, and there is a particularly striking difference in the inequality and precariousness of daily life between the affluent countries which we were able to examine and the poorer nations of Africa, Asia and Latin America. As this paper has tried to demonstrate, the issue of how economic well-being can best be measured makes a difference to country rankings of total well-being, such as the Human Development Index, even among the most affluent nations. The next task is to construct a better measure of the impact of sustainability, inequality and insecurity on "command over resources" for the citizens of the other nations of the world.

\section{Appendix 1: Constructing the Components of the IndeX of ECONOMIC WELL-BEING}

This appendix summarizes briefly how the practical details of estimation of the four key components of our Index of Economic Well-Being (IEWB) used in 
TABLE A1

Components and Variables of the Index of Economic Well-Being

\begin{tabular}{ll}
\hline \hline Basic Component & Sub-components \\
\hline Consumption flows (0.25) & Real total consumption (NCU per capita) \\
& Real current government spending on goods and services excluding \\
& debt service (NCU per capita) \\
& Adjustments for changes in working time, life expectancy and \\
& household economies of scale \\
& Real capital stock (including housing) (NCU per capita) \\
& Real R\&D stock (NCU per capita) \\
Stocks of wealth (0.25) & Real stock of human capital (NCU per capita) \\
& Real stock of natural resources (NCU per capita) \\
& Real net foreign debt (NCU per capita) \\
& Real social cost of environmental degradation $\left(\mathrm{CO}_{2}\right.$ emissions) \\
& (NCU per capita) \\
& Poverty intensity (Sen-Shorrocks-Thon Index) \\
& Income inequality (Gini coefficient) \\
Equality (0.25) & Risk from unemployment \\
Security (0.25) & Risk to financial security from illness \\
& Risk from single parenthood poverty \\
& Risk from poverty in old age \\
\hline
\end{tabular}

Weights in brackets for the "equal weighting" version of the Index.

$\mathrm{NCU}=$ National Currency Units (PPP adjusted, converted to US\$).

this paper-consumption flows, stocks of wealth, equality, and security-differ from our previous work (see Osberg and Sharpe, 2002b).

The formula for the overall index follows:

$$
\begin{aligned}
\mathrm{IEWB}= & 0.25[\mathrm{C}+\mathrm{G}+\mathrm{UP}+\mathrm{WT}]+0.25[\mathrm{~K}+\mathrm{R} \& \mathrm{D}+\mathrm{HC}+\mathrm{NC}+-\mathrm{D}-\mathrm{ED}] \\
& +[(0.1875)(\mathrm{LIM})+(0.0625) \mathrm{Gini}]+0.25[(\mathrm{POP} 1) \mathrm{UR}+(\mathrm{POP} 2) \mathrm{ILL} \\
& +(\mathrm{POP} 3) \mathrm{SPP}+(\mathrm{POP} 4) \mathrm{OLD}]
\end{aligned}
$$

where:

IEWB $=$ index of economic well-being

$\mathrm{C}=$ real per capita adjusted equivalent personal consumption

$\mathrm{G}=$ real per capita current government spending excluding debt charges

$\mathrm{WT}=$ working time adjustment

$\mathrm{UP}=$ real value of per capita unpaid labor

$\mathrm{K}=$ real per capita capital stock (including housing)

$\mathrm{R} \& \mathrm{D}=$ real per capita stock of research and development

$\mathrm{NR}=$ real per capita stock of natural resource wealth

$\mathrm{HC}=$ real per capita stock of human capital

$\mathrm{D}=$ real per capita net foreign debt

$\mathrm{ED}=$ real per capita social costs of environmental degradation (CO2 emissions)

LIM = poverty intensity (Sen-Shorrocks-Thon Index)

Gini $=$ Gini coefficient for post-fisc (after tax and transfers) money income

$\mathrm{UR}=$ risk from unemployment; POP1 $=$ P1/POPALL

$\mathrm{ILL}=$ risk to financial security from illness; POP2 $=$ P2/POPALL

$\mathrm{SPP}=$ risk from single parenthood poverty; POP3 $=$ P3/POPALL

$\mathrm{OLD}=$ risk from poverty in old age; POP4 $=$ P4/POPALL

POPALL $=$ P1 + P2 + P3 + P4; P1 = population aged 15-64; P2 = all persons; $\mathrm{P} 3=$ married women with children; $\mathrm{P} 4=$ population aged $45-64$ 


\section{A1.1. Average Consumption Flows}

Data on aggregate real personal consumption per capita expressed in national currency units, and in constant prices, are available from the OECD National Accounts publication. However, to calculate trends in effective consumption flows we add adjustments for changes in leisure, household size and life expectancy. Osberg and Sharpe (2002b) discuss in some detail the measurement of each element-here we emphasize only the issues raised when one uses the IEWB as the index of "command over resources," which is part of the HDI.

In particular, life expectancy is a specific component of the HDI and we have every reason to believe that having a long life is an important component of wellbeing - but for both economic and non-economic reasons. We include an adjustment for life expectancy under "access to resources" because people care both about how much they consume per year, and how many years they get to consume it. If one wants to measure the "command over resources" of people now alive, the economic value of consumption during these extra years of life should be included in the total consumption flows of individuals (see Usher, 1980). However, if life itself is valuable, then one also has a reason for including life expectancy as an argument in an index of well-being that is quite distinct from the "more consumption (over more years)" rationale, and this reasoning justifies including average life expectancy as one of the three components of the Human Development Index, independently of the consumption level of individuals during extra years of life.

To obtain an estimate of the average impact on "command over resources" of decreased mortality, we adjust per capita consumption flows in each year upward by the percentage increase in average life expectancy relative to the base year (1980), which is equivalent to measuring the expected value of undiscounted lifetime consumption. ${ }^{24}$

To ensure comparability of consumption per capita estimates across countries given international differences in life expectancy, the estimates of life expectancy in the United States are used as a benchmark and estimates for other countries adjusted by the ratio of that country's life expectancy to the U.S. estimate. Consumption is thus adjusted upward in countries with higher life expectancy than the United States and downward in countries with lower life expectancy. Implicitly this means that we are valuing extra years of life differently in different countries and at different times, because the current average level of consumption differs across countries and over time. This is appropriate in a measure of economic well-being or command over resources, but economics is only part of a broader conception of well-being. It would be inappropriate (ethically and socially) in an index of overall "well-being" to imply that a life in a poor country is worth less than a life in a rich country. However, it is accurate to say

\footnotetext{
${ }^{24}$ Some recent research suggests we may be underestimating the importance of increased life expectancy for economic well-being. Murphy and Topel (2002) find that the gains in life expectancy between 1970 and 1990 in the United States were worth about \$2.8 trillion per year in the aggregate or about $\$ 12,000$ per person per year. Nordhaus (2002) finds that the value of increases in life expectancy over the twentieth century is about as large as the value of measured growth in non-health goods and services.
} 
that consumption (and economic well-being) during a lifetime is greater in a rich country.

Data on life expectancy are taken from the OECD Health Data CD-ROM. Between 1980 and 1999 (1999 is the last year for which data is available for all seven countries), all countries enjoyed increased life expectancy, but there was a significant variation across countries in the size of the increase, which is given in brackets: Norway (3.4 percent), the United States (4.1 percent), Canada (4.6 percent), Sweden (4.9 percent), United Kingdom (5.7 percent), Australia (5.9 percent), and Germany (6.6 percent). In terms of life expectancy in 1999, Sweden had the higher level at 79.5 years, followed by Australia (79.0), Canada (79.0), Norway (78.4), Germany (77.7), the United Kingdom (77.4), and in last place, the United States (76.7).

\section{Total Consumption Flows}

Total per capita consumption is defined as the sum of personal consumption (adjusted for changes in average household size and longevity of life), government services, and the adjusted relative value of working time. ${ }^{25}$ Between 1980 and 2001 the increase in real per capita total consumption flows was 24.7 percent in Sweden, but much higher in the United Kingdom (64.7 percent), Germany (55.1 percent) and Norway (52.1 percent). Australia (47.8 percent), the United States (46.8 percent) and Canada (32.2 percent) were intermediate cases.

\section{A1.2. Accumulation, Sustainability and the Intergenerational Bequest}

If we think of "economic well-being" in the sense of "command over resources," then both present and future command over resources are relevant to current economic well-being. Both the future consumption of the current generation and the well-being of future generations depend on the accumulation of real productive assets, broadly conceived to include natural and human resources as well as physical capital stock. These real stocks will determine whether a society is on a long-run sustainable trajectory of aggregate consumption, irrespective of the distribution among persons of financial and legal claims on aggregate consumption flows at the individual level.

Only if one is willing to assume that the aggregate savings rate, summed over all types of assets (public or private, priced or non-market) is always and everywhere optimal, can one ignore the division of current income between consumption and savings (as is implicit in, for example, use of GDP per capita as a measure of "command over resources"). We are not willing to make that assumption because: (1) individuals may have different value judgments/preferences for their own future income and the income of future generations, which implies differing

\footnotetext{
${ }^{25}$ We adjust consumption by the ratio of actual hours worked for person of working age relative to the benchmark of the United States in 1980. Countries having average annual hours worked less than the benchmark therefore get a positive adjustment to consumption and countries having more working time than the benchmark get a negative adjustment. Our methodology amounts to saying that at the margin, individuals ascribe a value equal to the after-tax average wage to changes in non-working time that are not due to unemployment fluctuations.
} 
criteria of "optimality"; and (2) given the empirical importance of assets that are not priced in the market (e.g. environmental assets), have substantial externalities (e.g. education or research and development) or are heavily influenced by public policy decisions (all assets), it is implausible to believe that optimality emerges automatically.

The physical capital stock includes residential and non-residential structures, machinery, and equipment in both the business and government sector-all of which enable future potential consumption flows, and economic well-being. In an era of rapid technological change, expenditure on R\&D is also a crucial ingredient in the ability of society to innovate and create wealth. Since current consumption levels could be increased by running down stocks of non-renewable natural resources or by exploiting renewable resources in a non-sustainable manner (at the cost of the consumption of future generations) or by degrading the environment, we also want to measure net changes in the value of natural resources and the cost of increased air and water pollution (in particular, carbon dioxide emissions) (see Fankhauser (1995), World Bank (1997)).

In Osberg and Sharpe (2002b) we discuss the detailed measurement choices necessary to get an accurate estimate of each of these assets. In addition, in a knowledge-based economy, the stock of skills embodied in the workforce is also a crucial determinant of future economic well-being. There is a strong relationship between educational attainment and individual income and there is substantial evidence that education yields significant social benefits, over and above its impact on individual earnings. ${ }^{26}$ Although school retention and participation in post-secondary education have increased dramatically in many countries over the last three decades, human capital is intangible and is not now counted in balance sheet estimates of national wealth.

This paper estimates investment in human capital from the cost side, using the cost per year of education expenditures at the primary, secondary and postsecondary levels. OECD data on the educational attainment of the 25-64 population and expenditure per student (available in both local currency and U.S. dollars) for the early childhood, primary, secondary, non-university tertiary and university level education are used to estimate the per capita stock of human capital. In order to distinguish clearly inter-country differences in the quantity of education obtained, as opposed to differences in its cost of production, we apply a common cost base (the cost of education in the United States) to all countries.

Since we are interested in an index of economic well-being, we want to know the stock of assets that will produce "command over resources" in future yearshence estimating the dollar value of "human capital" in the stock of education is appropriate, as part of the capital accumulation component of the Index of Economic Well-Being. However, in considering education as a separate, independent component of the "Human Development Index," the UNDP recognizes that education also has a deeper role to play. If education were only valuable as "human capital," then it would be double-counting for the HDI to include both education and GDP per capita, since GDP already includes both the expenditure of resources

\footnotetext{
${ }^{26}$ Wolfe and Haveman (2001, p. 245) conclude that in estimating the non-market effects of schooling "a conservative estimate of the value of non-labor market influences is of the same order of magnitude as estimates of the annual, marketed, earnings-based effects."
} 
needed to produce schooling and the increment to money income produced by education. However, if education is also valuable because it increases the human capability to lead a life of understanding and meaning, in which greater knowledge is in itself an aspect of a good life (see Anand and Sen, 2000), then it is appropriate to consider its contribution to well-being over and above its contribution to "command over resources." Hence, we do not consider it "double-counting" to include separately the dollar value of the human capital stock of education as a productive asset and an index of education as part of "human development."

\section{Estimates of Total Wealth}

As the estimates of the physical capital stock, the R\&D capital stock, net foreign debt, and environmental degradation are expressed in value terms, they can be aggregated and presented on a per capita basis. Net foreign debt per capita is a negative entry, while the social costs of $\mathrm{CO}_{2}$ emissions are subtracted from the stocks of wealth.

For the 1980-2001 period, estimates for the five components of the wealth stock included in this paper (Table 2) indicate per capita real wealth stocks increased by 15.7 percent in the United States, much less than Norway's 58.1 percent. Sweden (29.2 percent), the United Kingdom (37.3 percent), Australia (37.1 percent), Canada (42.1 percent), and Germany (36.1 percent) were intermediate cases.

\section{A1.3. Income Distribution: Inequality and Poverty}

Utilitarians would argue that a society's economic well-being would decline if a nation in which everyone has $\$ 500$ income became one in which half the population had $\$ 999$ and the other half had $\$ 1$. Average income would remain unchanged, but the more equal society is likely to generate more aggregate utility. ${ }^{27}$ A Rawlsian would agree with the diagnosis of declining well-being, but for a different reason - that the least well off now have $\$ 1$ instead of $\$ 500$ (for a strict Rawlsian, it would be irrelevant whether the newly affluent received $\$ 600, \$ 999$ or $\$ 9,999)$. The idea that the "Social Welfare/Economic Well-Being" generated by a given aggregate "command over resources" depends, in general, on both average income and the inequality of incomes has a long tradition in welfare economics, although there are important differences in emphasis and philosophical basis. Hence, in measuring the level of social welfare, the exact relative weight to be assigned to changes in average incomes, compared to changes in inequality or increases in poverty, cannot be specified by economic theory.

Our perspective can be seen as an attempt to find a transparent compromise between the Utilitarian and Rawlsian positions. If the economic well-being of the population is affected both by inequality in the distribution of income among all people and by the adequacy of incomes for the least well-off (i.e. the extent of poverty), there are two issues: (1) one's perspective on the importance of income distribution compared to trends in average income; and (2) one's view of the relative weight to be placed on poverty compared to inequality. We, therefore,

\footnotetext{
${ }^{27}$ Recognizing that an additional dollar of income means less to a millionaire than to a pauper, economists tend to agree that "diminishing marginal utility" is a reasonable assumption.
} 
suggest that a compound sub-index to recognize explicitly these issues would place some weight $(\beta=0.25)$ on a measure of inequality in the aggregate distribution of income (we use the Gini index of after-tax, after transfer household income, because we think relative deprivation is the crucial issue in inequality aversionsee Lambert (1989, pp. 122-8)) and some weight $(1-\beta)$ on a measure of poverty (we use a poverty line of one half median after tax equivalent income and the Sen-Shorrocks-Thon measure of poverty intensity - see Osberg and Xu (2000)). Linear Scaling is used to standardize variables to a uniform range. ${ }^{28}$

\section{A1.4. Security}

If the human situation is one of "living in the present, anticipating the future," then uncertainty and worry about what the future may hold will decrease the current economic well-being of risk averse or anxious individuals. Although people can try to avoid risk through social and private insurance, such mechanisms do not completely eliminate economic anxieties, which have to be considered a subtraction from well-being. This paper adopts a "named risks" approach to economic security, focusing on four key objective economic risks. Over fifty years ago, the United Nations' Universal Declaration of Human Rights stated:

Everyone has the right to a standard of living adequate for the health and well-being of himself and of his family, including food, clothing, housing and medical care and necessary social services, and the right to security in the event of unemployment, sickness, disability, widowhood, old age or other loss of livelihood in circumstances beyond his control. (Article 25) ${ }^{29}$

For this paper, as in Osberg and Sharpe (2002a), we construct measures of the percentage change over time in the economic risks associated with unemployment, illness, "widowhood" (interpreted here as single female parenthood) and old age. In each case, we model the risk of an economic loss associated with the event as a conditional probability, which itself is the product of a number of underlying probabilities. We weight the prevalence of economic risks by the proportion of the population that it affects. The core hypothesis underlying the measure of economic insecurity we propose is that changes in the subjective level of anxiety about a lack of economic safety are proportionate to changes in objective risk.

The economic risk associated with unemployment is modeled as the product of the risk of unemployment and the extent to which people are protected from the income losses of unemployment by unemployment insurance. In estimating the economic losses associated with illness, we assume that risk is proportional to the share of uninsured private medical care expenses in disposable income. Because divorce and separation have become the primary origins of single parent families and of poverty among single parent we model trends in this aspect of economic insecurity, as the product of: (the probability of divorce) $\times($ the poverty rate among single female parent families $) \times($ the average poverty gap ratio among single female parent families). Since income in old age is the result of a lifelong series of

\footnotetext{
${ }^{28}$ Note that this represents a change in our methodology.

${ }^{29}$ Today, the gender specificity of the language of 1948 will strike many people as odd-but Article 2 makes it clear that all rights are to be guaranteed to male and female persons equally.
} 
events and decisions, which we cannot hope to disentangle in this paper, we model the idea of "insecurity in old age" as the chance that an elderly person will be poor, and the average depth of that poverty.

To follow the convention that increases in the sub-components of the index of economic security are improvements, we want an index of "security" and not an index of "insecurity." Hence, since increases in health costs, single parent or elderly poverty risk and costs of unemployment are negative for economic wellbeing, we use the linearly scaled variable

$$
\frac{\text { Max - Value }}{\text { Max-Min }} \text {. }
$$

The four risks discussed above have been aggregated into an index of economic security using as aggregation weights the relative importance of the four groups in the population, normalized for all years to one.

The sources for the data underlying all Charts in the text can be found in the Index of Economic Well-being MS EXCEL database file, posted for free download at http://www.csls.ca/iwb/oecd.asp. Please follow the links for specific charts to find the most recent discussion of sources and any revision of data. Background data for additional OECD countries, as well as the seven countries which this paper considers (for which data are more reliable) are also presented.

\section{REFERENCES}

Anand, S. and A. Sen, "The Income Component of the Human Development Index," Journal of Human Development, 1(1), 83-106, 2000.

Atkinson, A. B., "Income Inequality in OECD Countries: Data and Explanations," CES-IFO Working Paper No. 881, November 2002.

Atkinson, A. B., B. Cantillon, E. Marlier, and B. Nolan, Social Indicators; The EU and Social Inclusion, Oxford University Press, Oxford, 2002.

Barr, N., The Welfare State as Piggy Bank: Information, Risk, Uncertainty and the Role of the State, Oxford University Press, Oxford, 2001.

Clark, Andrew, Fabrice Etilé, Fabien Postel-Vinay, Claudia Senik, and Karine Van der Straeten, Heterogeneity and Measures of Well-Being: Evidence from Twelve European Countries, Mimeo, October 2003.

Cobb, Clifford, Ted Halstead, and Jonathan Rowe, The Genuine Progress Indicator: Summary of Data and Methodology, Redefining Progress, San Francisco, 1995.

Dasgupta, P., Human Well-Being and the Natural Environment, Oxford University Press, Oxford, 2001.

Fankhauser, S., "Evaluating the Social Costs of Greenhouse Gas Emissions," Energy Journal, 15, 157-84, 1995.

Johansson, P. O., An Introduction to Modern Welfare Economics, Cambridge University Press, Cambridge, 1991.

Lambert, Peter, The Distribution and Redistribution of Income: A Mathematical Analysis, Basil Blackwell Publishers, Cambridge, Massachusetts and Oxford, U.K., 1989.

Land, Kenneth, "Social Indicators," in Edgar F. Borgatta and Rhonda V. Montgomery (eds), Encyclopedia of Sociology, revised edition, Macmillan, New York.

Murphy, Kevin and Robert Topel, "The Economic Value of Medical Research," in Kevin Murphy and Robert H. Topel (eds), Exceptional Returns, University of Chicago Press, Chicago, 2002.

Nordhaus, William and James Tobin, "Is Growth Obsolete?," in Economic Growth, Fiftieth Anniversary Colloquium V, National Bureau of Economic Research, New York, 1972.

Nordhaus, William, "The Health of Nations: The Contribution of Improved Health to Living Standards," in Kevin M. Murphy and Robert H. Topel (eds), Exceptional Returns, University of Chicago Press, Chicago, 2002. 
Osberg, Lars, "The Measurement of Economic Welfare," in David Laidler (coordinator), Approaches to Economic Well-Being, Vol. 26 of the Royal Commission on the Economic Union and Development Prospects for Canada (MacDonald Commission) University of Toronto Press, Toronto, 1985 a.

, "The Idea of Economic Well-Being," Paper presented at the 19th General Conference of the International Association for Research in Income and Wealth, Noordwijkerhout, Netherlands, August 25-31, Dalhousie University, June, Mimeo, 1985b.

-, "Economic Insecurity," Discussion Paper No. 88, Social Policy Research Centre, University of New South Wales, Sydney, Australia, 1998.

_ , "Long Run Trends in Income Inequality in the USA, UK, Sweden, Germany and CanadaA Birth Cohort View," Eastern Economic Journal, 29(1), 121-42, Winter 2003.

Osberg, Lars and Andrew Sharpe, "An Index of Economic Well-Being for Canada," paper presented at the CSLS Conference on the State of Living Standards and Quality of Life in Canada, October 30-31, Ottawa, Ontario (paper posted at www.csls.ca under conferences), also Research Paper R-99-3E, Applied Research Branch, Human Resources Development Canada, December 1998.

- "International Comparisons of Trends in Economic Well-Being," Social Indicators Research, 58(1-3), 349-82, June 2002a.

, "An Index of Economic Well-Being for Selected OECD Countries," The Review of Income and Wealth, 48(3), 291-316, September 2002b.

_. "Evaluer l'Indice du bien-etre economique dans les pays de l'OCDE," Travail et Emploi, 93, 73-94, Janvier 2003.

Osberg, Lars and Tim Smeeding, "Fair Inequality? An International Comparison of Attitudes to Pay Differentials," paper presented at 28th General Conference of the International Association of Research on Income and Wealth, August 23-27, 2004, Cork, Ireland and Canadian Economics Association, June 4, 2004, Ryerson University, Toronto, Ontario.

Osberg, Lars and Kuan Xu, "International Comparisons of Poverty Intensity: Index Decomposition and Bootstrap Inference,” Journal of Human Resources, 35(1), 51-81, Winter 2000.

Phipps, S., "The Well-Being of Young Canadian Children in International Perspective: A Functionings Approach," The Review of Income and Wealth, 48(4), 493-516, 2002.

Phipps, S. and L. Curtis, "Social Transfers and the Health Status of Mothers in Norway and Canada," Social Science and Medicine, 2003.

Phipps, S. and T. I. Garner, "Are Equivalence Scales the Same for the United States and Canada?," The Review of Income and Wealth, 40(1), 1-18, 1994.

Rawls, John, "Social Unity and Primary Goods," in Amartya Sen and Bernard Williams (eds), Utilitarianism and Beyond, Cambridge University Press, Cambridge, 159-86, 1982.

Sen, A. K., Development as Freedom, Alfred A. Knopf, 1999.

Solow, R. M., "Intergenerational Equity and Exhaustible Resources," The Review of Economic Studies, Vol. 41, Symposium on the Economics of Exhaustible Resources, 29-45, 1974.

Tawney, R. H., Equality, George Allen and Unwin, London, first published in 1931, 4th edition, reprinted in 1964.

United Nations in collaboration with Eurostat, International Monetary Fund, Organization for Economic Co-operation and Development, and World Bank, System of National Accounts 1993, Series F, No. 2, Rev. 4, joint publication by Eurostat, IMF, OECD, UN and the World Bank, New York, 1993.

United Nations Development Programme, Human Development Report, 2001, Oxford University Press, New York, 2001.

United Nations Development Programme, Human Development Report, 2004, available at http://hdr. undp.org/reports/global/2004/

Usher, Dan, The Measurement of Economic Growth, Basil Blackwell, Oxford, 1980.

Veenhoven, Ruut, World Database of Happiness, www.eur.nl/fsw/research/happiness, 2004.

Wolfe, B. and R. Haveman, "Accounting for the Social and Non-Market Benefits of Education," in John Helliwell (ed.), The Contribution of Human and Social Capital to Sustained Economic Growth and Well Being, International Symposium Report, Organization for Economic Co-operation and Development and Human Resource Development Canada, Paris and Ottawa, 203-50, 2001.

World Bank, "Expanding the Measure of Wealth: Indicators of Environmentally Sustainable Development," Environmentally Sustainable Development Studies and Monographs Series No. 17, World Bank, Washington, D.C., 1997. 